This report was prepared as an account of work sponsored by an agency of the United States Government. Neither the United States Government nor any agency thereof, nor any of their employees, makes any warranty, express or implied, or assumes any legal liability or responsibility for the accuracy, completeness, or usefulness of any information, apparatus, product, or process disclosed, or represents that its use would not infringe privately owned rights. Reference herein to any specific commercial product, process, or service by trade name, trademark, manufacturer, or otherwise does not necessarily constitute or imply its endorsement, recom. mendation, or favoring by the United States Government or any agency thereof. The views and opinions of authors expressed herein do not necessarily state or reflect those of the United States Government or any agency thereof.

\title{
THERMODYNAMICS OF AQUEOUS ELECTROLYTES AT HIGH TEMPERATURES BY THE ISOPIESTIC TECHNIQUE
}

\author{
H. F. Holmes and R. E. Mesmer \\ Chemical and Analytical Sciences Division \\ Oak Ridge National Laboratory \\ P. O. Box 2008, Bldg. 4500S, MS6110 \\ Oak Ridge, TN 37831-6110, U. S. A.
}

\begin{abstract}
Excess thermodynamic properties of a wide variety of aqueous electrolyte solutions at elevated temperatures have been determined with the ORNL high-temperature isopiestic facility. This unique experimental apparatus provides very precise results over the useful temperature range of 110 to $250^{\circ} \mathrm{C}$. The isopiestic method is a comparative technique which, in the present case, uses the Pitzer-Peiper-Busey formulation for $\mathrm{NaCl}(\mathrm{aq})$ as the reference electrolyte. At elevated temperatures the ion-interaction model of Pitzer continues to be the most useful description of the experimental results. Our experimental program has included the alkali metal chlorides, sulfates, hydroxides, bromides, and bisulfates, the alkaline earth metal chlorides, and several specific compounds of scientific and practical interest. Numerous common-ion mixed electrolyte solutions have also been investigated in this program. In general, the activity coefficients of all the studied electrolytes decrease with increasing temperature. However, prominent differences between members of the same family remain, particularly when considered as the excess Gibbs free energy. The tendency for ion association increases with increasing temperature and becomes a factor at the higher temperatures. Trends and specific effects are illustrated with examples taken from the database generated in our high-temperature thermodynamic program.
\end{abstract}

\section{INTRODUCTION}

Most of the data contained in compilations of osmotic coefficients (of the solvent) and activity coefficients (of the solute) for aqueous electrolytes have been obtained using the isopiestic method. This technique was pioneered by Robinson and Stokes and brought to a mature state of development at $25^{\circ} \mathrm{C}$ through numerous studies by these authors. [1] Isopiestic measurements at $25^{\circ} \mathrm{C}$ are still an active area of research with the results of Rard being perhaps the prime example.[2] With few exceptions, isopiestic measurements at temperatures above ambient have been confined almost exclusively to our laboratory, where the first efforts were reported in 1958 and useful results began to appear in 1961.[3,4] These first studies at elevated temperatures depended on manual adjustment of an internal weighing mechanism and several of them, for unknown reason(s), have not been reproduced in later experiments. In a 1972 study of concentrated electrolyte mixtures the apparatus was improved with the major advance being automation of the weighing mechanism.[5] The present

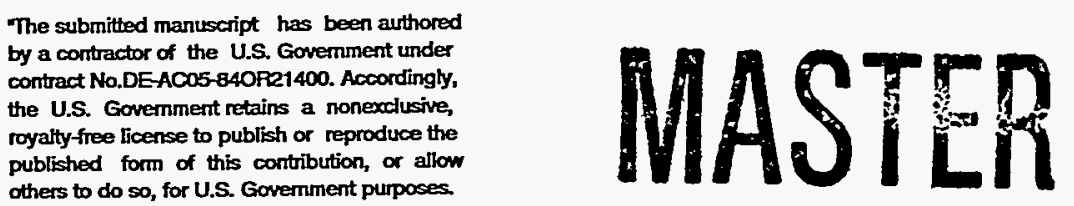




\section{DISCLAIMER}

Portions of this document may be illegible in electronic image products. Images are produced from the best available original document. 
program began in 1976 and has produced precise isopiestic results for numerous electrolyte systems, both pure and mixed, at elevated temperatures through $250^{\circ} \mathrm{C}$.[6-24] A recent isopiestic program, operating at $100.3^{\circ} \mathrm{C}$, has produced some useful results and involves an adaption of the classical $25^{\circ} \mathrm{C}$ technique of interrupting the experiment and weighing the samples with an analytical balance.[25] This procedure is also used in our low-temperature isopiestic program which operates in the temperature range of $25-75^{\circ} \mathrm{C}$. [26] Patterson and his co-workers have published some important isopiestic data in the same temperature range using a similar adaption of the classical technique.[27]

\section{EXPERIMENTAL TECHNIQUE}

An isopiestic experiment consists essentially of allowing two or more containers of solutions (our discussion will be limited to aqueous solutions but the isopiestic method is completely general) to reach equilibrium with a common vapor phase in a closed system at constant temperature and pressure. At equilibrium the water activity will be constant throughout the system, i. e., all solutions will have the same water activity. The starting point is to define an osmotic coefficient $\phi$ in terms of the water activity $a_{w}$ as

$$
\phi=-1000 \ln \left(\mathrm{a}_{\mathrm{w}}\right) /\left(\nu \mathrm{mM}_{\mathrm{w}}\right),
$$

where $\nu$ is the number of ions per molecule, $m$ is the molality, and $M_{w}$ is the molecular weight of water. For any two solutions the following relationship is true:

$$
\nu_{1} \mathrm{~m}_{1} \phi_{1}=\nu_{2} \mathrm{~m}_{2} \phi_{2} \text {. }
$$

Equation (2) is the fundamental relationship for an isopiestic experiment and gives the two requirements for a successful experiment. One is that one of the solutions must serve as a reference substance, i. e., its thermodynamic properties are assumed to be known with the required degree of accuracy. Pitzer, Peiper, and Busey's model for the thermodynamic properties of $\mathrm{NaCl}(\mathrm{aq})$ serves as our reference with the dielectric constant of water from Bradley and Pitzer and the PVT properties of water from Haar, Gallagher, and Kell.[28-30] Secondly, there must be some provision for determining the equilibrium molalities of the solutions with the necessary precision and accuracy. The classical technique of interrupting the experiment and weighing the containers of solution does not work so well when the experimental temperature is above the normal boiling point of the solvent. The heart of the ORNL high-temperature isopiestic facility is an in-situ electromagnetic balance capable of weighing the samples without interruption of the experiment. The solutions equilibrate while resting on a massive copper block (serving as a heat sink) inside a sealed stainless steel pressure vessel which serves as the isopiestic chamber. Water activity in the chamber can be changed by addition or removal of water through a stainless steel capillary tube. The entire apparatus is housed in a constant-temperature air bath. Reagent grade, or better, chemicals were used for the preparation of all solutions. Moles of solute in the sample cups were determined from the mass of the dry salt, if possible, or from a mass aliquot of a stock solution which had been analyzed by a gravimetric technique (e. g., $\mathrm{AgCl}$ ). More detail concerning both the isopiestic method and the ORNL high-temperature isopiestic facility can be found in a recent review.[31]

\section{RESULTS AND DISCUSSION}

Since space is far too limited for a general and detailed accounting of all of the systems which have been studied with the ORNL high-temperature isopiestic facility we will limit ourselves to a listing of such systems, a few examples, some general trends, and a few interesting features. Some typical osmotic coefficient results are shown in Fig. 1. These results are for the alkali metal bromides and the alkali metal hydroxides and provide an interesting contrast which is also true at $25^{\circ} \mathrm{C}$. The normal order of osmotic (and activity) coefficients is a decrease with increasing ion size (crystal) as shown in Fig. 1. However, as also shown in Fig. 1, the exact reverse is observed for the alkali metal hydroxides. The postulated reason for this reversal in order is a type of ion-solvent interaction referred to as "localized hydrolysis" which can also be viewed as hydrogen bonding to give a solvent separated ion-pair.[1] Whatever the actual reason for the difference in order of the osmotic 
coefficients, it is observed at all temperatures for which experimental results have been obtained at the present time.

The lines through the points in Fig. 1 are least-squares fits of Pitzer's ion-interaction model to the experimental osmotic coefficient. [32] The fit is quite good, with a standard deviation of fit of about 0.003 in phi, which is somewhat better than we know the osmotic coefficient on a absolute basis. This model has been found to be useful over wide ranges of temperature for both single and mixed electrolyte systems. For the present purpose we are interested in the mathematical expressions for the osmotic and activity coefficients. These two coefficients are related through a suitable variation of the Gibbs-Duhem equation such as

$$
\ln \gamma=(\phi-1)+\int_{0}^{\mathrm{m}}(\phi-1) \mathrm{dm} / \mathrm{m}
$$

where $\gamma$ is the activity coefficient. In the ion-interaction model the osmotic coefficient is given by

$$
\phi=1+\left|\mathrm{z}_{+} \mathrm{z}_{-}\right| f^{\phi}+\left(2 \nu_{+} \nu_{-} / \nu\right) \mathrm{mB}^{\phi}+2\left\{\left(\nu_{+} \nu_{-}\right)^{3 / 2} / \nu\right\} \mathrm{m}^{2} \mathrm{C}^{\phi}
$$

Electronic charges and ion numbers are denoted by $z$ and $\nu$, respectively, with the subscripts + and - referring to cations and anions; also, $\nu=\nu_{+}+\nu_{.}$.The long-range electrostatic contribution $f^{\phi}$ is calculated from

$$
f^{\phi}=-\mathrm{A}_{\phi} \mathrm{I}^{1 / 2} /\left(1+b \mathrm{~b}^{1 / 2}\right)
$$

where $I$ is the ionic strength defined in the normal way, $\left\{\Sigma_{i}\left(m_{i} z_{i}^{2}\right)\right\} / 2$, and $A_{\phi}$ is the Debye-Hückel slope as defined by Pitzer.[32] $\mathrm{B}^{\phi}$, also known as the second virial coefficient, is defined as

$$
\mathrm{B}^{\phi}=\beta^{(0)}+\beta^{(1)} \exp \left(-\alpha 1^{1 / 2}\right)
$$

The numerical constants $\alpha$ and $\mathrm{b}$ are normally fixed at 2.0 and 1.2 , respectively, although it is sometimes preferable to use a different value for $\alpha .[13,18]$ Ion-interaction parameters $\beta^{(0)}, \beta^{(1)}$, and $\mathrm{C}^{\phi}$ are determined from a least-squares fit of the equation (4) to experimental results, osmotic coefficients in the present case. There is considerably more interest in the activity coefficient $\gamma$ which is given by

where the following definitions are used:

$$
\ln \gamma=\left|z_{+} z_{-}\right| f^{\gamma}+\left(2 \nu_{+} \nu_{-} / \nu\right) \mathrm{mB}^{\gamma}+2\left\{\left(\nu_{+} \nu_{-}\right)^{3 / 2} / \nu\right\} \mathrm{m}^{2} \mathrm{C}^{\gamma}
$$

$$
\begin{gathered}
f^{\gamma}=-\mathrm{A}_{\phi}\left\{\mathrm{I}^{1 / 2} /\left(1+\mathrm{bI}^{1 / 2}\right)+(2 / \mathrm{b}) \ln \left(1+\mathrm{bI}^{1 / 2}\right)\right\} \\
\mathrm{B}^{\gamma}=2 \beta^{(0)}+2 \beta^{(1)}\left\{1-\left(1+\alpha \mathrm{I}^{1 / 2}-\alpha^{2} \mathrm{I} / 2\right) \exp \left(-\alpha \mathrm{I}^{1 / 2}\right)\right\} /\left(\alpha^{2} \mathrm{I}\right) \\
\mathrm{C}^{\gamma}=(3 / 2) \mathrm{C}^{\phi}
\end{gathered}
$$

Equations (4) and (7) are consistent with equation (3) as they must be for thermodynamic consistency. Ion-interaction parameters obtained from the application of (4) to isopiestic results are used in equations (7) to (10) to compute the desired activity coefficients.

Activity coefficients (as $\ln \gamma$ ) as a function of ionic strength are shown in Fig. 2 for $\mathrm{KCl}(\mathrm{aq}$ ) and $\mathrm{SrCl}_{2}(\mathrm{aq})$ at three temperatures. These results illustrate one of the general trends that we have seen in all of our studies over this temperature range, i. e., the activity (and osmotic) coefficients monotonically decrease with increasing temperature. This monotonic decrease is not necessarily true in the temperature range from ambient $\left(25^{\circ} \mathrm{C}\right)$ to $100^{\circ} \mathrm{C}$, e.g., the alkali metal chlorides.[33] $\mathrm{KCl}$ and $\mathrm{SrCl}_{2}$ are representatives of two families which follow the "normal" trend with ion size, i. e., the activity coefficient decreases with increasing cation size.

In Fig. 3 we compare the activity coefficients (again as $\ln \gamma$ ) of a 2-1 charge type, $\mathrm{CaCl}_{2}(\mathrm{aq})$, and a 1-2 charge type, $\mathrm{Na}_{2} \mathrm{SO}_{4}(\mathrm{aq})$. The activity coefficients of Fig. 3 were calculated from our global models for these two electrolytes.[18,23] Although $\mathrm{CaCl}_{2}$ and $\mathrm{Na}_{2} \mathrm{SO}_{4}$ have identical long-range electrostatic (Debye-Hückel) contributions to $\ln \gamma$, their total activity coefficients are quite different. This difference is not limited to elevated temperatures as it is quite noticeable at $25^{\circ} \mathrm{C}$. There are two possible explanations for the differing behavior exhibited in Fig. 3 - association and hydration. We favor hydration effects as we have demonstrated a positive correlation between the activity coefficients and molar volumes for these two families that is consistent with larger values of the activity coefficient for the more strongly hydrated electrolytes.[18]

Outside of the research laboratory mixed-electrolyte systems (those having two or more cations and/or two or more anions) are far more common than single electrolyte systems.In recent years an 


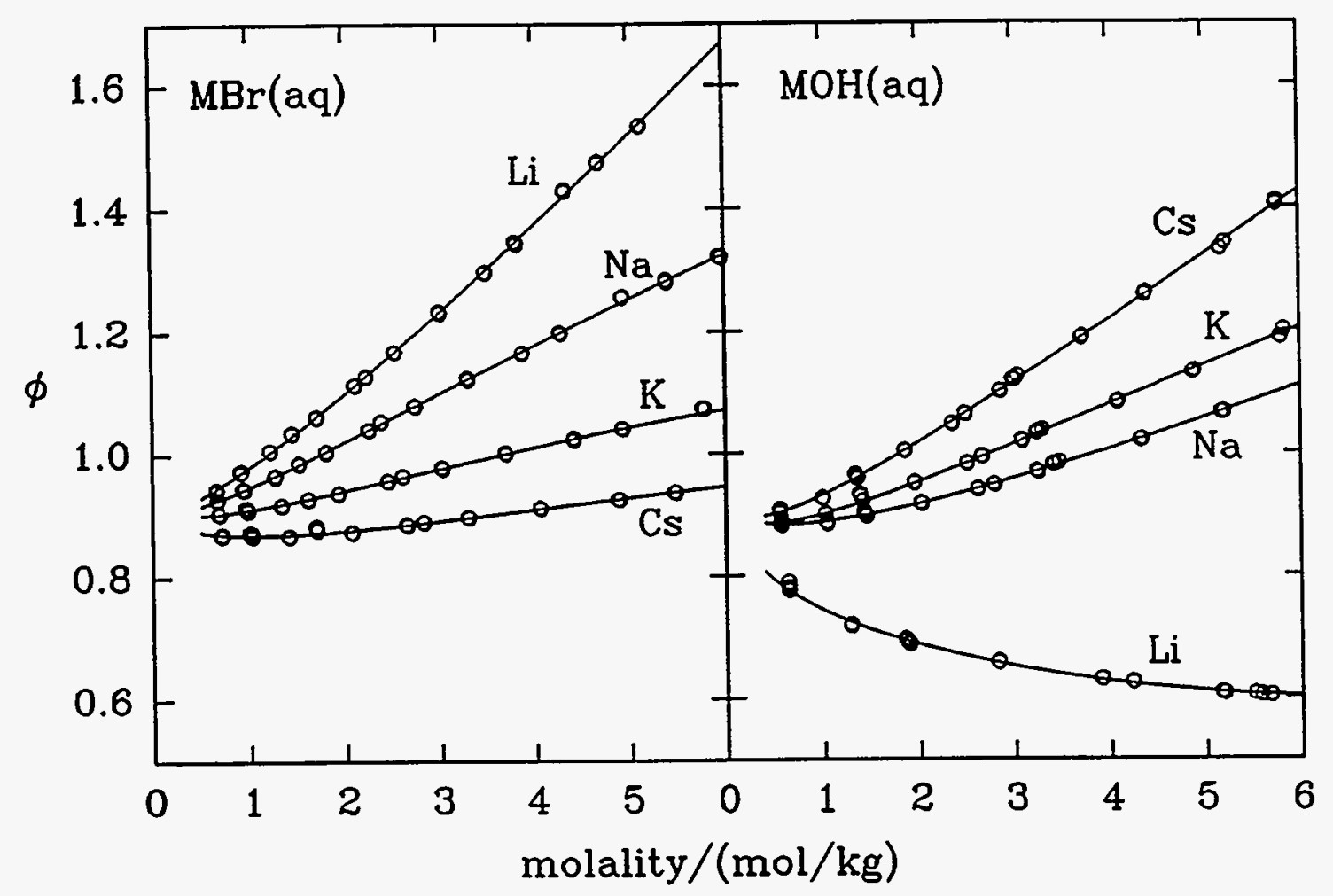

Figure 1. Osmotic coefficients of the alkali metal bromides and the alkali metal hydroxides as a function of molality at $140^{\circ} \mathrm{C}$.

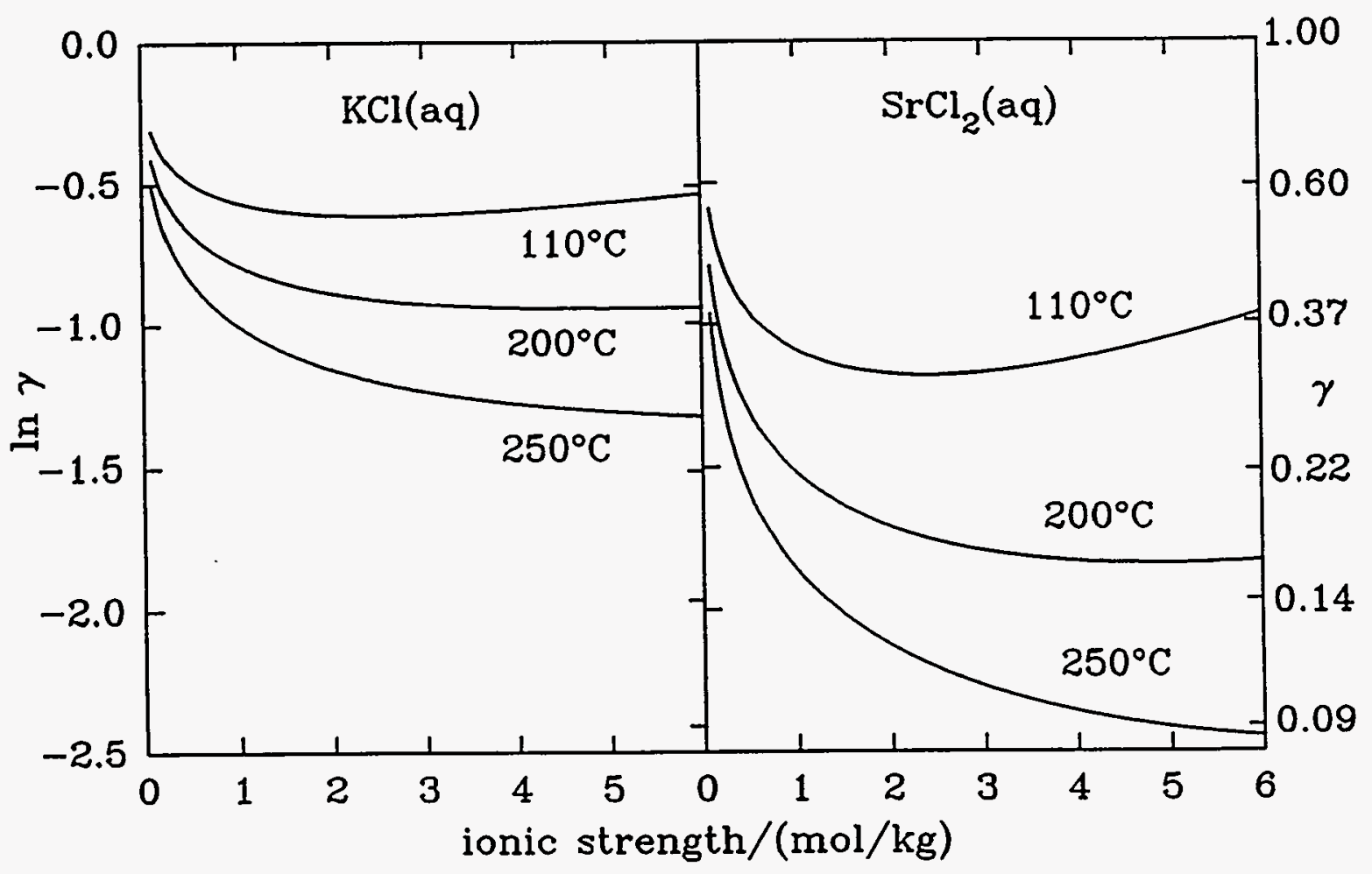

Figure 2. Activity coefficients (as $\ln \gamma$ ) of $\mathrm{KCl}(\mathrm{aq})$ and $\mathrm{SrCl}_{2}$ (aq) as a function of ionic strength at 110,200 , and $250^{\circ} \mathrm{C}$. 


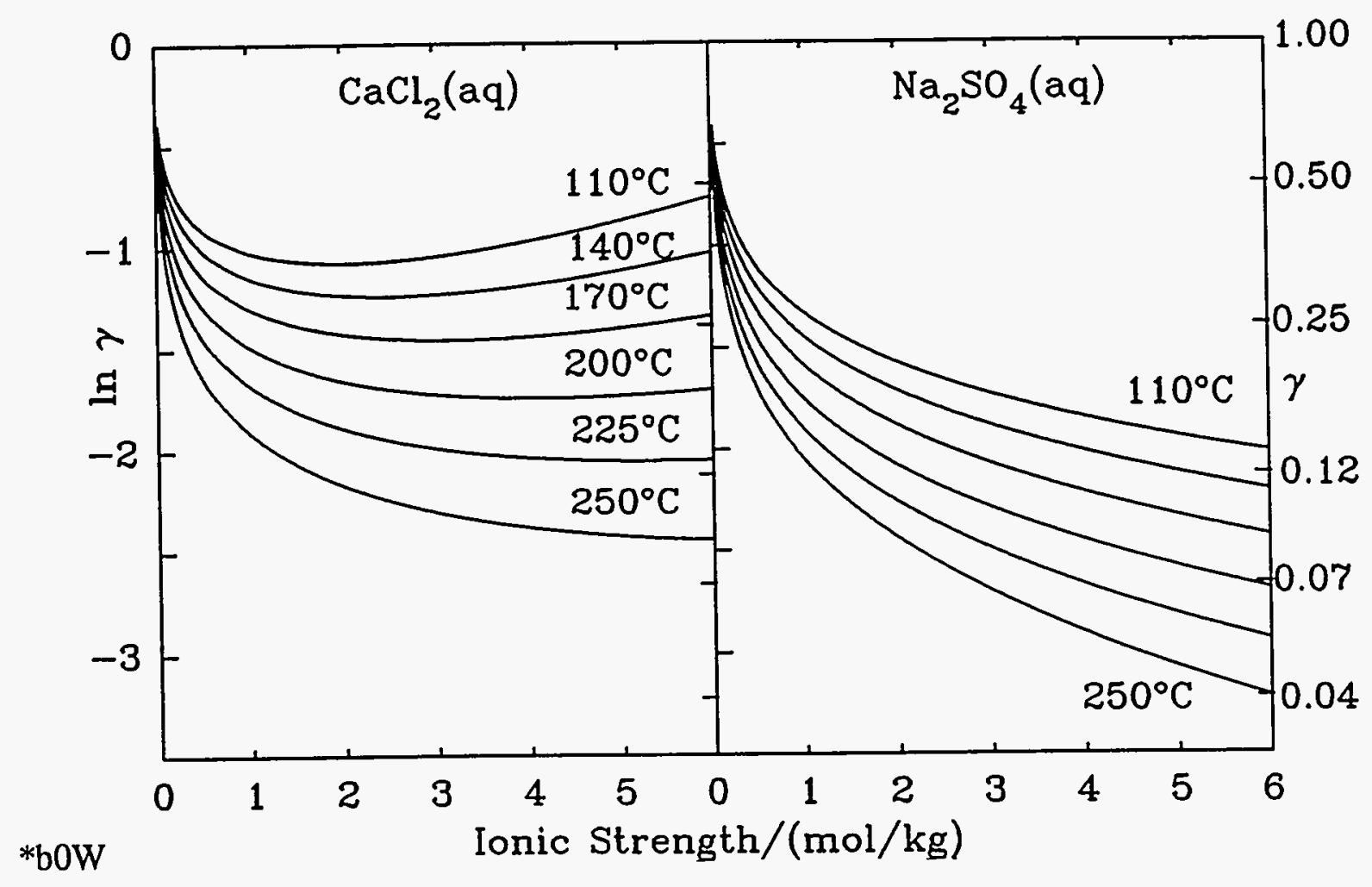

Figure 3. Activity coefficients (as In $\gamma$ ) of $\mathrm{CaCl}_{2}$ (aq) $\mathrm{Na}_{2} \mathrm{SO}_{4}$ (aq)as a function of ionic strength from 110 to $250^{\circ} \mathrm{C}$.

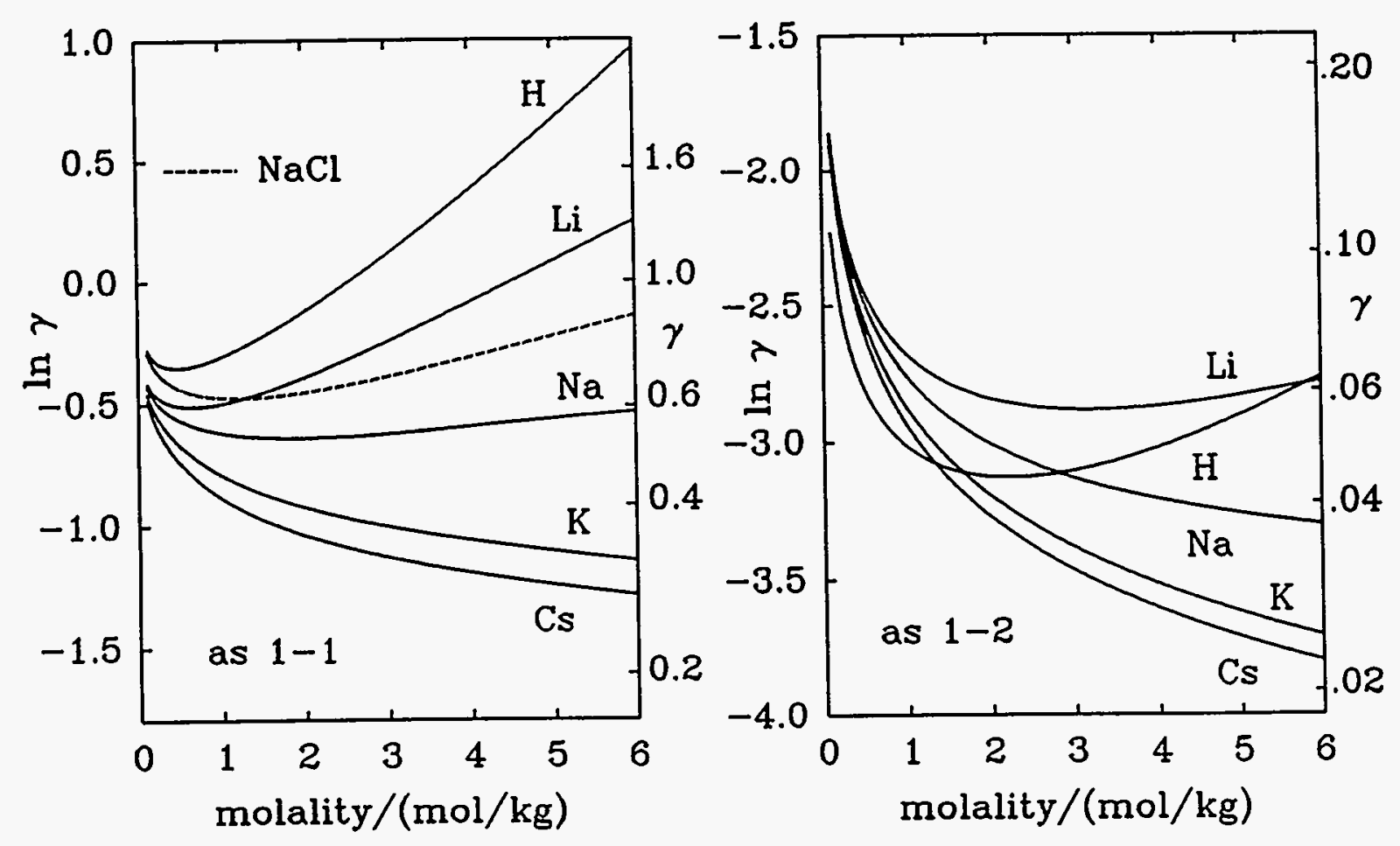

Figure 4. Activity coefficients (as $\ln \gamma$ ) of the alkali metal bisulfates (including sulfuric acid) at $100^{\circ} \mathrm{C}$ as $1-1$ and 1-2 charge types. 
increasing amount of attention has been focused on the properties of mixed electrolyte solutions at elevated temperatures. These studies are a welcome addition as high temperature mixtures are involved in various processes including, but limited to, steam generator chemistry (irrespective of the heat source), corrosion, geothermal brines and ore formation, and waste disposal (including nonnuclear). An isopiestic experiment, measuring only the properties of the solvent, is well-suited for the study of mixed electrolyte solutions. It is usually necessary to treat the results of such experiments within the framework of a thermodynamically consistent model. The ion-interaction treatment is such a model and it has been applied to a large number of aqueous solutions of mixed electrolytes at $25^{\circ} \mathrm{C}$.[34] The ion-interaction model has also been used quite successfully in high temperature studies of mixed electrolyte systems.[e. g., 16] The equations involved are not difficult but can be quite cumbersome, especially if the system contains several electrolytes of different charge types. Simplifications are possible for special situations, e. g., for mixing MX and NX, two 1-1 electrolytes with a common ion the osmotic coefficient is give by

$$
\phi=(1-\mathrm{y}) \phi_{\mathrm{MX}}^{*}+\mathrm{y} \phi_{\mathrm{NX}}^{*}+\mathrm{y}(1-\mathrm{y}) \theta_{\mathrm{MN}}+\mathrm{y}(1-\mathrm{y}) \mathrm{m}^{2} \psi_{\mathrm{MNX}}
$$

where the superscript $*$ indicates a property of a pure component at the same molality as the total molality of the mixture, $\mathrm{y}$ is the mole fraction of $\mathrm{NX}, \theta$ is a binary mixing parameter for mixing unlike ions of the same sign, and $\psi$ is the ternary parameter for mixing two unlike ions of the same sign with a third ion of the opposite sign. The equation for the activity coefficient is also quite simple, e. g., for component $M X$

$$
\ln \gamma_{\mathrm{MX}}=\ln \gamma_{\mathrm{MX}}^{*}+\Delta \phi^{*}+\mathrm{ym}\left\{\theta_{\mathrm{MN}}+(1-\mathrm{y} / 2) \mathrm{m} \psi_{\mathrm{MNX}}\right\}
$$

where $\Delta \phi^{*}$ is $\left(\phi_{\mathrm{NX}}^{*} \phi_{\mathrm{MX}}^{*}\right)$ and an analogous expression holds for component $\mathrm{NX}$.

For mixtures of $\mathrm{Na}$ with $\mathrm{Li}, \mathrm{K}$, or $\mathrm{Cs}$ at elevated temperatures the situation can be simplified even further as the ternary mixing parameter $\psi$ can be taken as zero. $[7,14,15]$ Also the binary mixing parameter $\theta$ can be adequately represented as a linear function of reciprocal temperature which means that the excess thermodynamics of mixing are quite simple for these systems. Mixing contributions for $\mathrm{Na}$ and $\mathrm{Ca}$ with $\mathrm{Cl}$ as the common anion are, surprisingly, quite small at high temperatures and can be neglected at low molalities. Mixtures of $\mathrm{Cs}$ and $\mathrm{Ba}$ with $\mathrm{Cl}$ as the common anion are the most complex that we have analyzed at the present time, requiring both binary and ternary mixing parameters with the mixing contributions being quite important, e. g., amounting to as much as 50 per cent of the trace activity coefficient of $\mathrm{BaCl}_{2}$ in the mixture.[16] It should be emphasized that it is the trace activity coefficient (an infinitely dilute component of a mixture) where the mixing contributions are at their maximum.

Sulfuric acid and the alkali metal bisulfates are examples of systems which are complicated by chemical equilibrium. Because of the partial ionization of the bisulfate anion, an aqueous solution of an alkali metal sulfate must be treated as a mixture of four component electrolytes. For the same reason, aqueous sulfuric acid is analyzed as a common ion mixture of two electrolytes (sulfate and bisulfate with hydrogen as a common cation). Using our isopiestic results as an experimental base we have developed a useful model for the excess thermodynamic properties of aqueous solutions sulfuric acid and the alkali metal bisulfates at temperatures to $225^{\circ} \mathrm{C}$.[19-21] The stoichiometric activity coefficients for these electrolytes can be computed either as a 1-1 or a 1-2 charge type. Activity coefficients of the alkali metal bisulfates at $100^{\circ} \mathrm{C}$ calculated on both bases are compared in Fig. 4. At this temperature and these molalities the bisulfate anion is no more than about 5 to 10 per cent ionized so the electrolytes do behave more like 1-1 charge types as can be seen from the dashed line which is the activity coefficient of $\mathrm{NaCl}(\mathrm{aq})$ at $100^{\circ} \mathrm{C}$. However, in the limit of infinite dilution (the basis for the standard state) these salts are completely dissociated and is the reason that the activity coefficients are normally reported on a 1-2 basis. The curve for sulfuric acid as a 1-2 has a different shape because of a common-ion effect which is absent in the metal bisulfates.

Aqueous solutions of electrolytes for which we have isopiestic results at elevated temperatures are listed in Table 1. The results for a substantial number of these systems have not yet been subjected to final analysis and publication. Their publication status can be ascertained from the reference number in brackets. Experiments dealing with a few of the systems in Table 1 were complicated by 
irreversible chemical reactions. For example, hydrolysis of $\mathrm{NiCl}_{2}$ and $\mathrm{CoCl}_{2}$ and volatility of the resulting $\mathrm{HCl}$ terminated experiments with these two systems at $140^{\circ} \mathrm{C}$. Studies of $\mathrm{NiSO}_{4}(\mathrm{aq})$ and $\mathrm{MgSO}_{4}$ (aq) were terminated at the same temperature because of irreversible solubility effects. Analysis of the unpublished results of Table 1 is a continuing activity.

Table 1. Aqueous Electrolytes Studied with the ORNL High-Temperature Isopiestic Facility

Single Electrolyte Systems

\begin{tabular}{lllllll}
\hline $\mathrm{LiCl}[11]$ & $\mathrm{LiOH}[24]$ & $\mathrm{LiBr}[24]$ & $\mathrm{MgCl}_{2}[6]$ & $\mathrm{H}_{2} \mathrm{SO}_{4}[19]$ & $\mathrm{LiHSO}_{4}[24]$ & $\mathrm{H}_{3} \mathrm{PO}_{4}[24]$ \\
$\mathrm{KCl}[6]$ & $\mathrm{NaOH}[24]$ & $\mathrm{NaBr}[24]$ & $\mathrm{CaCl}_{2}[6]$ & $\mathrm{Li}_{2} \mathrm{SO}_{4}[13]$ & $\mathrm{NaHSO}_{4}[20]$ & $\mathrm{NaH}_{2} \mathrm{PO}_{4}[24]$ \\
$\mathrm{CsCl}[11]$ & $\mathrm{KOH}[24]$ & $\mathrm{KBr}[24]$ & $\mathrm{SrCl}_{2}[10]$ & $\mathrm{Na}_{2} \mathrm{SO}_{4}[13]$ & $\mathrm{KHSO}_{4}[24]$ & $\mathrm{Na}_{2} \mathrm{HPO}_{4}[24]$ \\
& $\mathrm{CsOH}[24]$ & $\mathrm{CsBr}[24]$ & $\mathrm{BaCl}_{2}[10]$ & $\mathrm{K}_{2} \mathrm{SO}_{4}[13]$ & $\mathrm{CsHSO}_{4}[24]$ & $\mathrm{KH}_{2} \mathrm{PO}_{4}[24]$ \\
$\mathrm{CoCl}_{2}[9]$ & & & $\mathrm{Cs}_{2} \mathrm{SO}_{4}[13]$ & & $\mathrm{K}_{2} \mathrm{HPO}_{4}[24]$ \\
$\mathrm{NiCl}_{2}[9]$ & $\mathrm{MgSO}_{4}[12]$ & $\mathrm{NiSO}_{4}[12]$ & & & &
\end{tabular}

Common-Ion Mixed Electrolyte Systems

\begin{tabular}{llll}
\hline$\{\mathrm{Na}, \mathrm{K}\} \mathrm{Cl}[7]$ & $\{\mathrm{Ca}, \mathrm{Mg}\} \mathrm{Cl}[24]$ & $\mathrm{Na}\left\{\mathrm{Cl}, \mathrm{SO} \mathrm{O}_{4}\right\}[24]$ & $\mathrm{Na}\left\{\mathrm{OH}, \mathrm{Al}(\mathrm{OH})_{4}\right\}[24]$ \\
$\{\mathrm{Na}, \mathrm{Li}\} \mathrm{Cl}[14]$ & $\{\mathrm{Ca}, \mathrm{Sr}\} \mathrm{Cl}[24]$ & $\mathrm{Na}\{\mathrm{Cl}, \mathrm{Br}\}[24]$ & $\mathrm{Na}\left\{\mathrm{HPO}_{4}, \mathrm{H}_{2} \mathrm{PO}_{4}\right\}[24]$ \\
$\{\mathrm{Na}, \mathrm{Cs}\} \mathrm{Cl}[15]$ & $\{\mathrm{Ca}, \mathrm{Ba}\} \mathrm{Cl}[24]$ & $\mathrm{Na}\{\mathrm{Cl}, \mathrm{OH}\}[24]$ & $\mathrm{Na}\left\{\mathrm{SO}_{4}, \mathrm{HSO}_{4}\right\}[24]$ \\
$\{\mathrm{K}, \mathrm{Mg}\} \mathrm{Cl}[24]$ & $\{\mathrm{Na}, \mathrm{Mg}\} \mathrm{Cl}[24]$ & $\{\mathrm{Na}, \mathrm{Ca}\} \mathrm{Cl}[24]$ & $\{\mathrm{Cs}, \mathrm{Ba}\} \mathrm{Cl}[16]$ \\
$\{\mathrm{K}, \mathrm{Ca}\} \mathrm{Cl}[24]$ & & &
\end{tabular}

Research sponsored by the Division of Chemical Sciences, Office of Basic Energy Sciences, U.S. Department of Energy, under contract DE-AC05-84OR21400 with Martin Marietta Energy Systems, Inc.

\section{REFERENCES}

1. Robinson, R. A. and Stokes, R. H. Electrolyte Solutions, 2nd edition. Butterworth: London. 1968.

2. An example: Rard, J. A. (1990) Isopiestic determination of the osmotic and activity coefficients of aqueous $\mathrm{Lu}_{2}\left(\mathrm{SO}_{4}\right)_{3}$ at $25^{\circ} \mathrm{C}$. J. Solution Chem. 19, 525-541.

3. Soldano, B. A., Stoughton, R. W., Fox, R. J., and Scatchard, G. A High-Temperature Isopiestic Unit in The Structure of Electrolytic Solutions. John Wiley \& Sons: New York. 1959. chap. 14. 4. Patterson, C. S., Gilpatrick, L. O., and Soldano, B. A. (1960) The osmotic behavior of representative aqueous salt solutions at $100^{\circ} \mathrm{J}$. Chem. Soc. 2730-2734.

5. Braunstein, H. and Braunstein, J. (1971) Isopiestic studies of very concentrated aqueous electrolyte solutions of $\mathrm{LiCl}, \mathrm{LiBr}, \mathrm{LiNO}_{3}, \mathrm{Ca}\left(\mathrm{NO}_{3}\right)_{2}, \mathrm{LiNO}_{3}+\mathrm{KNO}_{3}, \mathrm{LiNO}_{3}+\mathrm{CsNO}_{3}$, and $\mathrm{Ca}\left(\mathrm{NO}_{3}\right)_{2}+\mathrm{CsNO}_{3}$ at 100 to $150^{\circ} \mathrm{C}$. J. Chem. Thermodynamics $3419-431$.

6. Holmes, H. F., Baes, C. F., Jr. and Mesmer, R. E. (1978) Isopiestic studies of aqueous solutions at elevated temperatures. I. $\mathrm{KCl}, \mathrm{CaCl}_{2}$, and $\mathrm{MgCl}_{2}$. J. Chem. Thermodynamics 10, 983-996.

7. Holmes, H. F., Baes, C. F., Jr. and Mesmer, R. E. 1979 Isopiestic studies of aqueous solutions at elevated temperatures. II. $\mathrm{NaCl}+\mathrm{KCl}$ mixtures. J. Chem. Thermodynamics 11, 1035-1050.

8. Holmes, H. F., Baes, C. F., Jr. and Mesmer, R. E. (1981) Isopiestic studies of aqueous solutions at elevated temperatures. III. $\left\{(1-\mathrm{y}) \mathrm{NaCl}+\mathrm{yCaCl}_{2}\right\}$. J. Chem. Thermodynamics 13, 101-113.

9. Holmes, H. F. and Mesmer, R. E. (1981) Isopiestic studies of aqueous solutions at elevated temperatures. IV. $\mathrm{NiCl}_{2}$ and $\mathrm{CoCl}_{2}$. J. Chem. Thermodynamics 13, 131-137. 
10. Holmes, H. F. and Mesmer, R. E. (1981) Isopiestic studies of aqueous solutions at elevated temperatures. V. $\mathrm{SrCl}_{2}$ and $\mathrm{BaCl}_{2}$. J. Chem. Thermodynamics 13, 1025-1033.

11. Holmes, H. F. and Mesmer, R. E. (1981) Isopiestic studies of aqueous solutions at elevated temperatures. VI. $\mathrm{LiCl}$ and $\mathrm{CsCl}$. J. Chem. Thermodynamics 13, 1035-1046.

12. Holmes, H. F. and Mesmer, R. E. (1983) Isopiestic studies of aqueous solutions at elevated temperatures. VII. $\mathrm{MgSO}_{4}$ and $\mathrm{NiSO}_{4}$. J. Chem. Thermodynamics 15, 709-719.

13. Holmes, H. F. and Mesmer, R. E. (1986) Isopiestic studies of aqueous solutions at elevated temperatures. VIII. The alkali-metal sulfates. J. Chem. Thermodynamics 18, 263-275.

14. Holmes, H. F. and Mesmer, R. E. (1988) Isopiestic studies of aqueous solutions at elevated temperatures. IX. $\{(1-\mathrm{y}) \mathrm{NaCl}+\mathrm{yLiCl}\} . J$. Chem. Thermodynamics 20, 1049-1060.

15. Holmes, H. F. and Mesmer, R. E. (1990) Isopiestic studies of aqueous solutions at elevated temperatures. 10. $\{(1-\mathrm{y}) \mathrm{NaCl}+\mathrm{yCsCl}\}$. J. Phys. Chem. 94, 7800-7805.

16. Holmes, H. F. and Mesmer, R. E. (1992) Isopiestic studies of aqueous solutions at elevated temperatures. $\mathrm{XI}$. $\left\{(1-\mathrm{y}) \mathrm{CsCl}+\mathrm{yBaCl}_{2}\right\}$. J. Chem. Thermodynamics 24, 829-841.

17. Holmes, H. F. and Mesmer, R. E. (1983) Thermodynamic properties of aqueous solutions of the alkali metal chlorides to 250 C. J. Phys. Chem. 87, 1242-1255.

18. Holmes, H. F. and Mesmer, R. E. (1986) Thermodynamics of aqueous solutions of the alkali metal sulfates. J. Solution Chem. 15, 495-518.

19. Holmes, H. F. and Mesmer, R. E. (1992) Isopiestic studies of $\mathrm{H}_{2} \mathrm{SO}_{4}(\mathrm{aq})$ at elevated temperatures. Thermodynamic properties. J. Chem. Thermodynamics 24, 317-328.

20. Holmes, H. F. and Mesmer, R. E. (1993) Isopiestic studies of $\mathrm{NaHSO}_{4}(\mathrm{aq})$ at elevated temperatures. Thermodynamic properties. J. Chem. Thermodynamics 25, 99-110.

21. Holmes, H. F. and Mesmer, R. E. (1994) An isopiestic study of $\left\{(1-\mathrm{y}) \mathrm{NaHSO}_{4}+\mathrm{yNa}_{2} \mathrm{SO}_{4}\right\}$ (aq) at elevated temperatures. J. Chem. Thermodynamics 26, 581-594.

22. Holmes, H. F. and Mesmer, R. E. (1992) Mixing effects in aqueous solutions at elevated temperatures. J. Solution Chem. 21, 713-724.

23. Holmes, H. F., R. H. Busey, J. M. Simonson, and Mesmer, R. E. (1994) $\mathrm{CaCl}_{2}$ at elevated temperatures. Enthalpies of dilution, isopiestic molalities, and thermodynamic properties. J. Chem. Thermodynamics 26, 271-298.

24. H. F. Holmes and R. E. Mesmer, unpublished results.

25. Fanghänel, Th., Grjotheim, K., Voigt, W., and Brendler, V. (1992) Thermodynamics of aqueous reciprocal salt systems. VI. Isopiestic determination of osmotic coefficients in mixtures of chlorides, bromides, and nitrates of lithium, sodium, potassium, and cesium at $100.3^{\circ} \mathrm{C}$. Acta. Chem. Scand. 46, 423-431 and previous work referenced here.

26. Palmer, D. A. and Sweeton, F. H., unpublished results.

27. Davis, T. M., Duckett, L. M., Garvey, C. E., Hollifield, J. M., and Patterson, C. S. Osmotic coefficients of aqueous $\mathrm{LiCl}$ and $\mathrm{CaCl}_{2}$ from their isopiestic ratios to $\mathrm{NaCl}$ at $50^{\circ} \mathrm{C}$. J. Chem. Eng. Data 31, 54-55 and previous work referenced here.

28. Pitzer, K. S., Peiper, J. C. and Busey, R. H. (1984) Thermodynamic properties of aqueous sodium chloride solutions. J. Phys. Chem. Ref. Data 13, 1.

29. Bradley, D. J. and Pitzer, K. S. (1979) Thermodynamics of electrolytes. 12. Dielectric properties of water and Debye-Hückel parameters to $350^{\circ} \mathrm{C}$ and $1 \mathrm{kbar}$. J. Phys. Chem. 83, 15991603.

30. Haar, L., Gallagher, J. S., Kell, G. S. (1984) NBS/NRC Steam Tables. Hemisphere, 320p.

31. Rard, J. A., Platford, R. F. Experimental methods: isopiestic in Activity Coefficients in Electrolyte Solutions. Pitzer, K. S.: editor. CRC Press: Boca Raton. 1991, chap. 5.

32. Pitzer, K. S. (1973) Thermodynamics of electrolytes. I. Theoretical basis and general equations. J. Phys. Chem. 77, 268-277.

33. Lindsay, W. T.,Jr. and Liu, C.-t. (1971) Osmotic coefficients of one molal alkali metal chloride solutions over a $300^{\circ}$ temperature range. J. Phys. Chem. 75, 3723-3727.

34. Pitzer, K. S. and Kim, J. J. (1974) Thermodynamics of electrolytes. IV. Activity and osmotic coefficients for mixed electrolytes. Amer. Chem. Soc. J. 96, 5701-5707. 